\title{
Serum Klotho Levels Contribute to the Prevention of Disease Progression
}

This article was published in the following Dove Press journal:

International Journal of General Medicine

\section{Kaori Nakanishi \\ Makoto Nishida \\ Manabu Taneike \\ Ryohei Yamamoto \\ Toshiki Moriyama \\ Keiko Yamauchi-Takihara}

Health Care Division, Health and Counseling Center, Osaka University, Osaka, Japan
Correspondence: Keiko Yamauchi-Takihara Health Care Division, Health and Counseling Center, Osaka University, I-I7

Machikaneyama, Toyonaka, Osaka 560-0043, Japan

Tel +8I-6-6850-60I2

Fax+8I-6-6850-6040

Email takihara@wellness.hss.osaka-u.ac.jp
Background: Assessing the progression of a disorder from its pre-clinical state is important in the prevention of various diseases. In the present study, we evaluated the role of serum levels of $\alpha$ Klotho $(\alpha \mathrm{Kl})$ in the progression of several pre-clinical disorders.

Methods: This cohort study included 80 males who underwent their annual health checkup during the entry period between April 2005 and March 2008. Physical and biochemical parameters were obtained from all subjects. The associations of baseline serum levels of soluble $\alpha \mathrm{Kl}$ ( $\mathrm{s} \alpha \mathrm{Kl})$ with the progression of the disorders were assessed in the study.

Results: Baseline serum levels of $\mathrm{s} \alpha \mathrm{K} 1$ were significantly lower in subjects developing a high fasting plasma glucose (FPG) level than in subjects not developing a high FPG level. Logistic multivariable analysis showed that baseline serum levels of s $\alpha \mathrm{K} 1$ and FPG levels significantly associated with a high FPG level progression. It is suggested that low s $\alpha \mathrm{Kl}$ levels are associated with the progression of hyperglycemia. Evaluation of serum levels of $\mathrm{s} \alpha \mathrm{Kl}$ in subjects with multiple disorders revealed that those with more pre-clinical disorders progression tended to show lower saKl levels.

Conclusion: A decrease in serum levels of $\mathrm{s} \alpha \mathrm{Kl}$ could be associated with the progression of pre-clinical disorders.

Keywords: $\alpha$ Klotho, metabolic disorder, hyperglycemia, hypertriglyceridemia, hypertension

\section{Introduction}

It is well-known that the pre-clinical state of disorders, including obesity, hypertension, dyslipidemia, hyperglycemia, and hyperuricemia, is a serious risk factor for developing various diseases, such as cardiovascular disease, stroke, and type 2 diabetes mellitus. Moreover, as represented by the metabolic syndrome, cluster of these disorders would be a more serious risk for these diseases than a single disorder. $^{1-3}$ Recently, several studies reported the relationship between these diseases and Klotho (Kl). ${ }^{4-6}$

$\mathrm{K} 1$ was originally discovered as an anti-aging gene, Klotho. Klotho mutant mice have short life spans and exhibit multiple aging phenotypes, including skin atrophy, ectopic calcification, osteoporosis, atherosclerosis, and pulmonary emphysema. The gene encodes a single-pass transmembrane protein $\alpha \mathrm{Kl}$, which is primarily expressed in the distal tubule of kidneys, parathyroid gland, and choroid plexus. $^{7,8} \alpha \mathrm{Kl}$ regulates mineral metabolism and has an anti-inflammatory effect. ${ }^{9}$ A soluble form of $\alpha \mathrm{Kl}$, which is produced by shedding the transmembrane form, is detected in serum. ${ }^{10}$ Serum levels of soluble $\alpha \mathrm{Kl}(\mathrm{s} \alpha \mathrm{Kl})$ show several protective effects and is reported to relate with inflammatory cytokines. ${ }^{11,12}$ 
Focusing on the protective aspect of $\mathrm{s} \alpha \mathrm{Kl}$, we previously reported the unique association of serum levels of $\mathrm{s} \alpha \mathrm{K} 1$ with smoking and psychological stress. ${ }^{13,14} \mathrm{We}$ demonstrated that smoking and stressed condition increased serum levels of $\mathrm{s} \alpha \mathrm{Kl}$ in men. Moreover, s $\alpha \mathrm{K} 1$ levels associated with interleukin (IL)-6, suggesting that $s \alpha \mathrm{K} 1$ regulates IL- 6 . As $s \alpha \mathrm{K} l$ has protective effects, we concluded that increased serum levels of s $\alpha \mathrm{Kl}$ might be a compensatory response to protect against the harmful effects of smoking and psychological stress.

s $\alpha \mathrm{K} 1$ levels are reduced in some diseases, including type 2 diabetes mellitus and coronary artery disease. ${ }^{6,15}$ However, the association of s $\alpha \mathrm{K} 1$ with pre-clinical disorders has not been well studied. Assessing the development of disorders is important to prevent diseases and disease progression. Thus, in the present study, we evaluated the role of $s \alpha \mathrm{K} 1$ in preventing disease progression by assessing the association of serum levels of saKl with several pre-clinical disorders.

\section{Methods}

\section{Study Subjects}

This study was designed as a prospective cohort study of employees at the Osaka University. The subjects were individuals who underwent an annual health checkup in the Osaka University Health and Counseling Center during the entry period between April 2005 and March 2008. The inclusion criteria for this study were as follows: (1) male subjects, (2) ages of 40 and 60 years, (3) with no underlying disease. Information on their medical history, current treatments, and smoking status was obtained via questionnaires. From 874 individuals who met the inclusion criteria, 88 subjects were randomly selected for the study. Among the 88 subjects, eight were excluded because of no follow-up between their baseline visit and March 2018 . The final study cohort consisted of 80 men with at least one follow-up visit (Figure 1). This study was carried out in accordance with the Declaration of Helsinki and the ethics guidelines for clinical research from the Ministry of Health, Labour and Welfare and the Ministry of

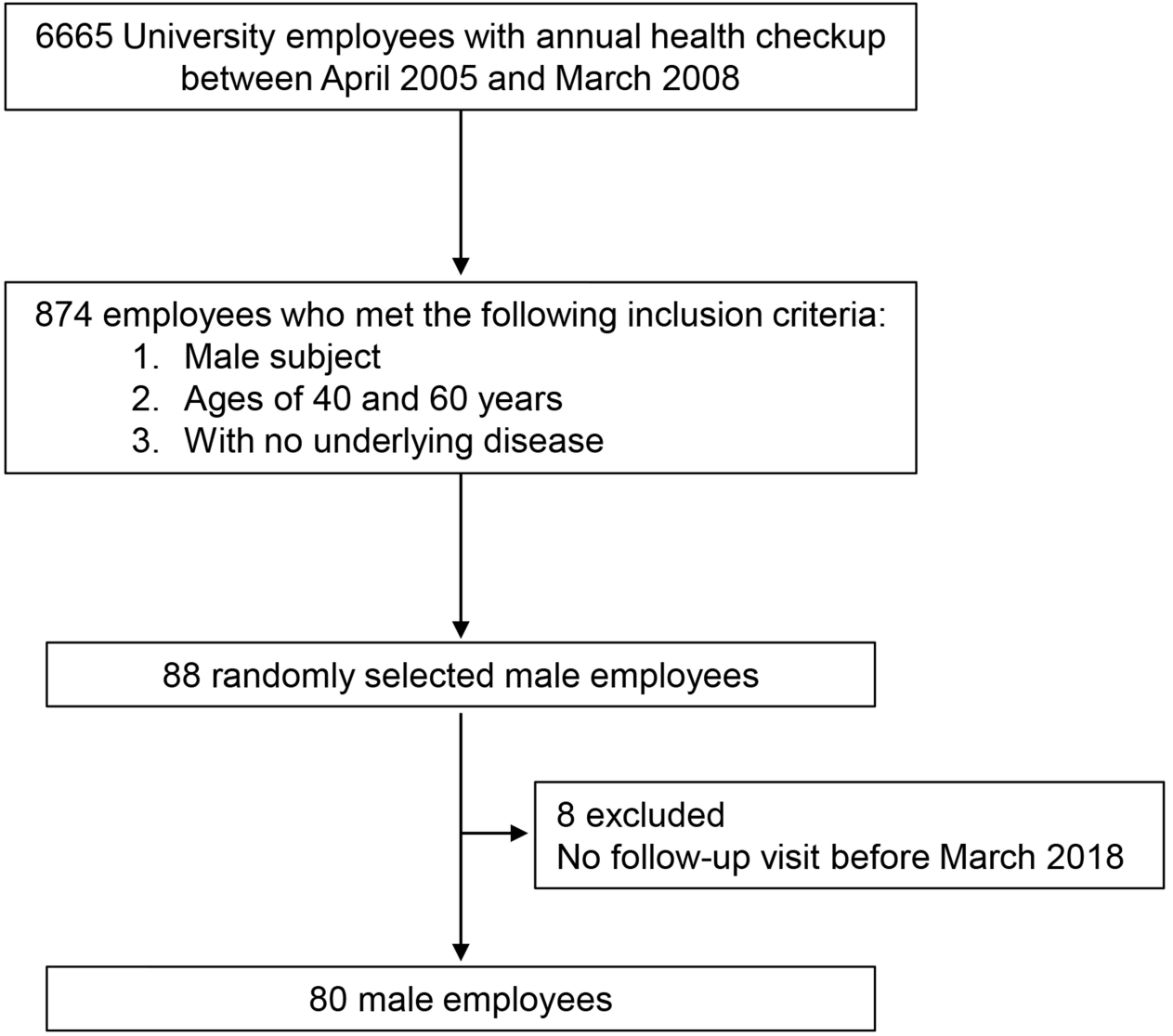

Figure I Flow diagram of inclusion and exclusion of the study subjects. 
Education, Culture, Sports, Science and Technology. All experimental protocols in this study were approved by the Ethics Committee of Health and Counseling Center, Osaka University and written informed consent was obtained from all subjects prior to participation in the study.

\section{Physical and Biochemical Parameters}

As the baseline data, physical and biochemical parameters were obtained from all subjects at their first visit during the entry period. Body mass index (BMI: body weight $(\mathrm{kg})$ divided by squared height $\left(\mathrm{m}^{2}\right)$ ), waist circumference (WC) at the umbilical level, systolic blood pressure (SBP), and diastolic blood pressure (DBP) were measured as physical parameters.

Serum was collected from subjects between 9 and 11 $\mathrm{AM}$ after an overnight fast and kept at $\leq-20^{\circ} \mathrm{C}$ until assayed. Serum concentrations of creatinine $(\mathrm{Cr})$, uric acid (UA), triglycerides (TG), low-density lipoproteincholesterol (LDL-C), fasting plasma glucose (FPG), and $\mathrm{s} \alpha \mathrm{Kl}$ were measured as biochemical parameters. Serum levels of $s \alpha \mathrm{Kl}$ were measured with a sandwich enzymelinked immunoassay system according to the manufacturer's instructions (Immuno-Biological Laboratories, Takasaki, Japan).

\section{Pre-Clinical Disorder Assessment}

Pre-clinical disorders were categorized as follows: overweight was defined as BMI $\geq 25 \mathrm{~kg} / \mathrm{m}^{2}$ according to the recommendations of the World Health Organization; abdominal obesity was defined as $\mathrm{WC} \geq 85 \mathrm{~cm}$ according to the guideline for abdominal obesity in Japanese ${ }^{16}$ high blood pressure was defined as SBP $\geq 135 \mathrm{mmHg}$ and/or DBP $\geq 85 \mathrm{mmHg}$ using the guideline for hypertension in Japanese. ${ }^{17}$ In the final stages of the study, we used SBP $\geq$ $140 \mathrm{mmHg}$ and/or DBP $\geq 90 \mathrm{mmHg}$ to define hypertension; a high Cr level was defined as $\mathrm{Cr} \geq 1.05 \mathrm{mg} / \mathrm{dL}$ using the upper normal value limit; and a high UA level was defined as UA $\geq 8 \mathrm{mg} / \mathrm{dL}$ by Japanese guideline for the management of hyperuricemia. ${ }^{18}$ According to the criteria of the Japan Atherosclerosis Society, hypertriglyceridemia and hyper-LDL cholesterolemia were defined as $\mathrm{TG} \geq$ $150 \mathrm{mg} / \mathrm{dL}$ and LDL-C $\geq 140 \mathrm{mg} / \mathrm{dL}$, respectively. ${ }^{19}$ A high FPG level was defined as FPG $\geq 100 \mathrm{mg} / \mathrm{dL}$ according to the criteria of the Japan Diabetes Society. ${ }^{20}$

Each pre-clinical disorder category was assessed to all study subjects. When assessing each disorder, we excluded subjects whose baseline data exceeded the values defined above. Therefore, among the 80 subjects, overweight: 20 , abdominal obesity: 32, high blood pressure: 29 , high $\mathrm{Cr}$ level: 7, high UA level: 7, hypertriglyceridemia: 17 , hyperLDL cholesterolemia: 24, and high FPG level: 10 subjects were excluded regarding each pre-clinical disorder assessment. The onset of each disorder was defined as the time when values measured at the follow-up visit exceeded the defined values or those at the initiation of treatment for the disorder. Hypertension, hypertriglyceridemia, and high FPG were used as factors for evaluating multiple preclinical disorders.

The term "progression of pre-clinical disorders" or "pre-clinical order progression" was used when the measurement values at the follow-up visit were progressing from normal range to the defined pre-clinical disorder range.

\section{Statistical Analyses}

All statistical analyses were performed using STATA 14 (STATA Corp LLC, College Station, TX, USA). The distribution of continuous variables was tested by the Shapiro-Wilk test. Normally distributed variables are presented as means \pm standard deviation; non-normally distributed variables are reported as medians with the interquartile range. Student's $t$-test, Mann-Whitney $U$-test, or chi-squared test were used to compare the difference between the two groups. Multivariable logistic regression analysis was performed to evaluate the predictive risk factors for pre-clinical disorders progression. Variables were entered into the multivariable model using forward selection ( $\mathrm{p}<0.2$ included). To compare the predictive risk factors, we constructed the Receiver operator characteristic (ROC) curves and determined their area under the curve (AUC). ${ }^{21}$ For multigroup comparisons, Dunnett's test was used to compare groups and the nptrend command of STATA software was used for the trend test. Statistical significance was set at $\mathrm{P}<0.05$.

\section{Results}

\section{Serum Levels of saKI Were Low in Subjects Developing Pre-Clinical Disorders}

As shown in Table 1, we confirmed that there were no significant differences in baseline characteristics between the study subjects $(n=80)$ and individuals who met the inclusion criteria $(\mathrm{n}=874)$. The mean duration of followup of the study subjects was $6.3 \pm 3.1$ years. The median 
Table I Baseline Characteristics

\begin{tabular}{|c|c|c|c|}
\hline & Study Subjects & Individuals Who Met the Inclusion Criteria & P-value \\
\hline $\mathrm{n}$ & 80 & 874 & \\
\hline Age (years) & $48(42-52)$ & $45(42-5 I)$ & 0.52 \\
\hline BMI $\left(\mathrm{kg} / \mathrm{m}^{2}\right)$ & $23.5 \pm 2.8$ & $23.7 \pm 2.9$ & 0.51 \\
\hline$W C(\mathrm{~cm})$ & $83.1 \pm 7.3$ & $84(78-89)$ & 0.33 \\
\hline $\mathrm{SBP}(\mathrm{mmHg})$ & $123(114-133)$ & $122(112-130)$ & 0.27 \\
\hline $\mathrm{DBP}(\mathrm{mmHg})$ & $80(7 I-87)$ & $78(72-86)$ & 0.66 \\
\hline $\mathrm{Cr}(\mathrm{mg} / \mathrm{dl})$ & $0.8 \pm 0.1$ & $0.8(0.7-0.9)$ & 0.63 \\
\hline UA (mg/dl) & $6.0 \pm 1.3$ & $6.0 \pm 1.2$ & 0.94 \\
\hline TG (mg/dl) & $89(67-125)$ & $105(78-130)$ & 0.36 \\
\hline LDL-C (mg/dl) & $125(107-146)$ & $125(104-14 \mid)$ & 0.62 \\
\hline FPG $(\mathrm{mg} / \mathrm{dl})$ & $88(83-93)$ & 90 (87-94) & 0.59 \\
\hline
\end{tabular}

Note: Data are expressed as means \pm SD or medians (interquartile range).

Abbreviations: BMI, body mass index; WC, waist circumference; SBP, systolic blood pressure; DBP, diastolic blood pressure; Cr, creatinine; UA, uric acid; TG, triglycerides; LDL-C, low-density lipoprotein-cholesterol; FPG, fasting plasma glucose.

age at the time of enrollment was $48(42-52)$ years. The mean serum level of $\mathrm{s} \alpha \mathrm{Kl}$ was $500 \pm 172 \mathrm{pg} / \mathrm{mL}$.

Table 2 shows the associations of serum levels of $\mathrm{s} \alpha \mathrm{Kl}$ with the progression of each pre-clinical disorder. Baseline serum levels of s $\alpha \mathrm{Kl}$ were significantly lower in subjects developing a high FPG level than in subjects not developing a high FPG level ( $p=0.004)$. In subjects with the progression of abdominal obesity, high blood pressure, high $\mathrm{Cr}$ level, high UA level, hypertriglyceridemia, and hyper-LDL cholesterolemia, baseline s $\alpha \mathrm{Kl}$ levels tended to be lower than in subjects without progression of those disorders, however significant differences were not shown. It is suggested that low serum levels of $\mathrm{s} \alpha \mathrm{Kl}$ might promote the progression of pre-clinical disorders, especially hyperglycemia.

During their follow-up period, 20 subjects were diagnosed with some diseases; including hypertension, dyslipidemia, type 2 diabetes mellitus, hyperuricemia, and cardiac disease. We evaluate the difference of s $\alpha \mathrm{K} l$ levels in subjects with diseases $(539 \pm 262 \mathrm{pg} / \mathrm{mL})$ between the subjects without diseases $(509 \pm 166 \mathrm{pg} / \mathrm{mL})$ and confirmed that there was no significant difference $(p=0.64)$.

\section{Low s $\alpha \mathrm{KI}$ Levels is Suggested to Predict Hyperglycemia}

We further evaluate the relationship between serum levels of $\mathrm{s} \alpha \mathrm{Kl}$ and the progression of a high FPG level. Table 3 shows the baseline characteristics of subjects with or without progression of a high FPG level. Multivariable logistic regression analysis showed that low level of s $\alpha \mathrm{K} 1$ and high baseline FPG level were independent predictive factors for the progression of a high FPG level (Table 4). Evaluating each AUC, both FPG and s $\alpha \mathrm{Kl}$ levels showed moderate accuracy with the progression of a high FPG level (Figure 2). Adding both factors slightly increased the AUC to 0.84, however a significant difference was not shown.

Moreover, we divided the study subjects into two groups according to the saKl levels and compared the frequency of developing a high FPG level in the low $(310 \pm 76 \mathrm{pg} / \mathrm{mL})$ and high $(609 \pm 112 \mathrm{pg} / \mathrm{mL}) \mathrm{s} \alpha \mathrm{Kl}$ groups. Individuals in the low $\mathrm{s} \alpha \mathrm{Kl}$ group were significantly more likely to develop a high FPG level than those in the high $\mathrm{s} \alpha \mathrm{K}$ l group $\left(\chi^{2}(1)=8.34, \mathrm{p}=0.0004\right)$.

These results suggest that decreased serum levels of s $\alpha \mathrm{K} l$ would be a predictive factor for the progression of hyperglycemia.

\section{Association of saKI Levels with Disorders in Never-Smokers}

We previously reported that a smoking habit upregulated the serum levels of $s \alpha \mathrm{Kl} .{ }^{13}$ Therefore, we assessed the smoking population in the study subjects and the association of serum levels of s $\alpha \mathrm{K} l$ with hypertension using the hypertension definition: $\mathrm{SBP} \geq 140 \mathrm{mmHg}$ and/or DBP $\geq 90 \mathrm{mmHg}$ (Table 5). Among the subjects studied, there were 44 smokers and 36 never-smokers. The baseline serum level of $\mathrm{s} \alpha \mathrm{K} l$ in the smoker group was $541 \pm 158 \mathrm{pg} / \mathrm{mL}$. This was significantly higher than that in the never-smoker group $(455 \pm 175 \mathrm{pg} / \mathrm{mL}, \mathrm{p}=$ 0.029). Serum levels of $\mathrm{s} \alpha \mathrm{Kl}$ in subjects developing hypertension were significantly higher in smokers than in never-smokers $(\mathrm{p}=0.041)$. Among never-smoker group, serum levels of $\mathrm{s} \alpha \mathrm{K} l$ tended to be lower in 
Table 2 Baseline Serum Levels of Soluble Alpha-Klotho $(s \alpha \mathrm{KI})$ in the Subjects with or without Pre-Clinical Disorder Progression

\begin{tabular}{|c|c|c|c|c|c|}
\hline \multicolumn{3}{|l|}{ Pre-Clinical Disorders } & \multirow{2}{*}{$\begin{array}{l}n \\
9 \\
51\end{array}$} & \multirow{2}{*}{$\begin{array}{l}\text { saKI (pg/mL) } \\
531 \pm|7| \\
485 \pm 159\end{array}$} & \multirow{2}{*}{$\begin{array}{l}\text { P-value } \\
0.493\end{array}$} \\
\hline Overweight & $\begin{array}{l}(+) \\
(-)\end{array}$ & $\begin{array}{l}\text { BMI } \geq 25\left(\mathrm{~kg} / \mathrm{m}^{2}\right) \\
\text { BMI }<25\left(\mathrm{~kg} / \mathrm{m}^{2}\right)\end{array}$ & & & \\
\hline Abdominal obesity & $\begin{array}{l}(+) \\
(-)\end{array}$ & $\begin{array}{l}W C \geq 85(\mathrm{~cm}) \\
W C<85(\mathrm{~cm})\end{array}$ & $\begin{array}{l}17 \\
31\end{array}$ & $\begin{array}{l}485 \pm 170 \\
497 \pm 160\end{array}$ & 0.831 \\
\hline High blood pressure & $\begin{array}{l}(+) \\
(-)\end{array}$ & $\begin{array}{l}\text { SBP/DBP } \geq 135 / 85(\mathrm{mmHg}) \\
\text { SBP/DBP }<135 / 85(\mathrm{mmHg})\end{array}$ & $\begin{array}{l}21 \\
30\end{array}$ & $\begin{array}{l}496 \pm 145 \\
529 \pm 186\end{array}$ & 0.487 \\
\hline High Cr level & $\begin{array}{l}(+) \\
(-)\end{array}$ & $\begin{array}{l}\mathrm{Cr} \geq \mathrm{I} .05(\mathrm{mg} / \mathrm{dl}) \\
\mathrm{Cr}<\mathrm{l} .05(\mathrm{mg} / \mathrm{dl})\end{array}$ & $\begin{array}{l}3 \\
70\end{array}$ & $\begin{array}{l}399 \pm 185 \\
504 \pm 164\end{array}$ & 0.507 \\
\hline High UA level & $\begin{array}{l}(+) \\
(-)\end{array}$ & $\begin{array}{l}\mathrm{UA} \geq 8.0(\mathrm{mg} / \mathrm{dl}) \\
\mathrm{UA}<8.0(\mathrm{mg} / \mathrm{dl})\end{array}$ & $\begin{array}{l}12 \\
61\end{array}$ & $\begin{array}{l}431 \pm 155 \\
511 \pm 172\end{array}$ & 0.138 \\
\hline Hypertriglyceridemia & $\begin{array}{l}(+) \\
(-)\end{array}$ & $\begin{array}{l}\text { TG } \geq 150(\mathrm{mg} / \mathrm{dl}) \\
\mathrm{TG}<150(\mathrm{mg} / \mathrm{dl})\end{array}$ & $\begin{array}{l}24 \\
39\end{array}$ & $\begin{array}{l}506 \pm 181 \\
524 \pm 174\end{array}$ & 0.497 \\
\hline Hyper-LDL cholesterolemia & $\begin{array}{l}(+) \\
(-)\end{array}$ & $\begin{array}{l}\mathrm{LDL}-\mathrm{C} \geq \mathrm{I} 40(\mathrm{mg} / \mathrm{dl}) \\
\mathrm{LDL}-\mathrm{C}<\mathrm{I} 40(\mathrm{mg} / \mathrm{dl})\end{array}$ & $\begin{array}{l}24 \\
32\end{array}$ & $\begin{array}{l}527 \pm 169 \\
536 \pm 176\end{array}$ & 0.850 \\
\hline High FPG level & $\begin{array}{l}(+) \\
(-)\end{array}$ & $\begin{array}{l}\mathrm{FPG} \geq 100(\mathrm{mg} / \mathrm{dl}) \\
\mathrm{FPG}<100(\mathrm{mg} / \mathrm{dl})\end{array}$ & $\begin{array}{l}19 \\
51\end{array}$ & $\begin{array}{l}402 \pm 168^{*} \\
543 \pm 160\end{array}$ & 0.004 \\
\hline
\end{tabular}

Note: *P $<0.005$ versus high FPG level $(-)$ group.

Abbreviations: BMI, body mass index; WC, waist circumference; SBP, systolic blood pressure; DBP, diastolic blood pressure; Cr, creatinine; UA, uric acid; TG, triglycerides; LDL-C, low-density lipoprotein-cholesterol; FPG, fasting plasma glucose.

Table 3 Baseline Characteristics in Subjects with or without Progression of High Fasting Plasma Glucose Level

\begin{tabular}{|c|c|c|c|}
\hline & High FPG Level (+) FPG $\geq 100(\mathrm{mg} / \mathrm{dL})$ & High FPG Level (-) FPG $<100(\mathrm{mg} / \mathrm{dL})$ & P-value \\
\hline $\mathrm{n}$ & 19 & 51 & \\
\hline Age (years) & $49(42-54)$ & $45(4 I-5 I)$ & 0.15 \\
\hline BMI $\left(\mathrm{kg} / \mathrm{m}^{2}\right)$ & $22.6 \pm 2.0$ & $23.3 \pm 2.6$ & 0.28 \\
\hline WC $(\mathrm{cm})$ & $80.8 \pm 6.1$ & $82.9 \pm 6.8$ & 0.23 \\
\hline $\mathrm{SBP}(\mathrm{mmHg})$ & $120 \pm 13$ & $123 \pm 12$ & 0.40 \\
\hline $\mathrm{DBP}(\mathrm{mmHg})$ & $79 \pm 9$ & $78 \pm 9$ & 0.55 \\
\hline $\mathrm{Cr}(\mathrm{mg} / \mathrm{dl})$ & $0.8 \pm 0.1$ & $0.8 \pm 0.1$ & 0.77 \\
\hline UA (mg/dl) & $6.1 \pm 0.9$ & $6.0 \pm 1.5$ & 0.60 \\
\hline TG (mg/dl) & $77(60-111)$ & $86(65-121)$ & 0.55 \\
\hline LDL-C (mg/dl) & $126(118-140)$ & $121(102-146)$ & 0.22 \\
\hline $\mathrm{FPG}(\mathrm{mg} / \mathrm{dl})$ & $92 \pm 4^{*}$ & $85 \pm 6$ & $<0.0001$ \\
\hline
\end{tabular}

Note: $* \mathrm{P}<0.005$ versus high FPG level $(-)$ group.

Abbreviations: BMI, body mass index; WC, waist circumference; SBP, systolic blood pressure; DBP, diastolic blood pressure; $\mathrm{Cr}$, creatinine; UA, uric acid; TG, triglycerides; LDL-C, low-density lipoprotein-cholesterol; FPG, fasting plasma glucose.

Table 4 Multivariable Logistic Analysis: Risk Factors for High Fasting Plasma Glucose Level

\begin{tabular}{|l|l|l|l|}
\hline Risk Factors & Odds Ratio & 95\% Confidence Interval & P-value \\
\hline Age (per 10years) & 1.69 & $0.56-5.14$ & 0.354 \\
FPG (per 10mg/dl) & $9.54^{*}$ & $2.21-41.1$ & 0.002 \\
s $\alpha$ KI (per 100pg/mL) & $0.59 *$ & $0.38-0.90$ & 0.015 \\
\hline
\end{tabular}

Note: $* \mathrm{P}<0.05$.

Abbreviations: FPG, fasting plasma glucose; s $\alpha \mathrm{KI}$, soluble alpha-Klotho. 


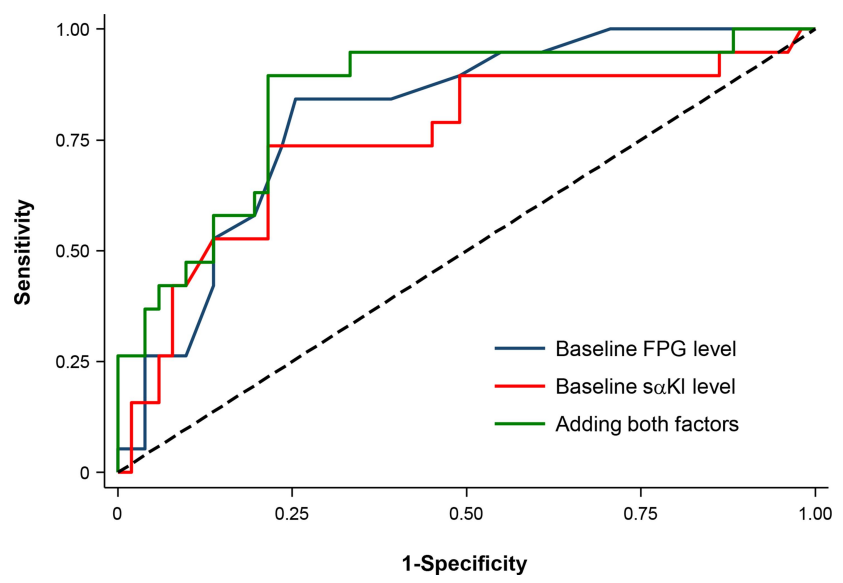

Figure 2 Receiver operation characteristic (ROC) curves of predictors for progression of a high fasting plasma glucose (FPG) level. The area under the curve (AUC) for baseline FPG and soluble alpha-Klotho (s $\alpha \mathrm{KI})$ levels were 0.81 ( $95 \%$ confidence interval, $0.70-0.91)$ and 0.75 (95\% confidence interval, 0.6I-0.89), respectively. The AUC of adding both factors was 0.84 ( $95 \%$ confidence interval, 0.73-0.95).

subjects with the progression of hypertension than in subjects without progression of hypertension. As smoking status might affect s $\alpha \mathrm{Kl}$ levels, we confirmed the association between $\mathrm{s} \alpha \mathrm{K} 1$ levels and each pre-clinical disorder in the never-smoker group. We found that serum levels of $s \alpha \mathrm{Kl}$ in the never-smoker group were significantly lower for subjects developing a high FPG level $(322 \pm 94 \mathrm{pg} / \mathrm{mL})$ than in subjects without this change $(509 \pm 174 \mathrm{pg} / \mathrm{mL}, \mathrm{p}=0.0005)$.

\section{Serum Levels of saKI in Subjects with Multiple Disorders}

As the serum levels of s $\alpha \mathrm{Kl}$ were low in subjects with the progression of pre-clinical disorders, we evaluated the s $\alpha \mathrm{K} 1$ levels in subjects with multiple disorders: hypertension, hypertriglyceridemia, and high FPG. To exclude the influence of smoking, the never-smoker group was used for comparison. As shown in Figure 3, subjects with multiple disorders progression tended to have lower serum levels of $s \alpha \mathrm{K} 1$. We also found that s $\alpha \mathrm{Kl}$ levels in subjects

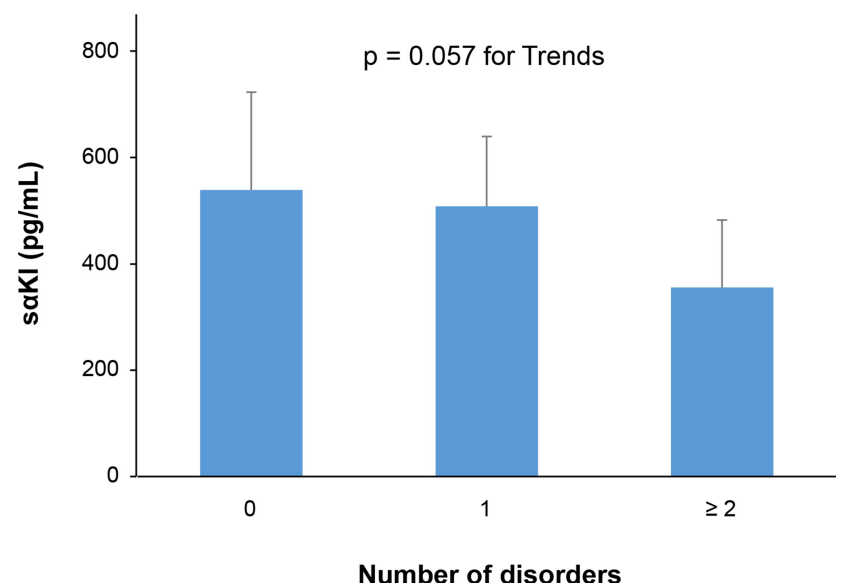

Figure 3 Serum levels of soluble alpha-Klotho $(s \alpha \mathrm{KI})$ in subjects with multiple preclinical disorders. Association between serum levels of $s \alpha \mathrm{KI}$ and the number of disorders: hypertension, hypertriglyceridemia, and high fasting plasma glucose. The number of disorders was classified into three groups: $0=$ no disorder progression $(n=14), 1=$ one disorder progression $(n=8), \geq 2=$ more than two disorders progression $(n=6)$. Data are shown as means \pm SD.

with more than two disorders progression tended to be lower than those in subjects with no disorder.

\section{Discussion}

The number of people developing pre-clinical states of disorders, such as hypertension, dyslipidemia, and hyperglycemia, is increasing in modern society. Since the morbidity and mortality of diseases caused by these disorders are still high, ${ }^{22}$ assessing their progression is important. The present study identified a relationship between $s \alpha \mathrm{K} 1$ levels and the progression of pre-clinical disorders.

$\alpha \mathrm{K} 1$ functions as a co-receptor for fibroblast growth factor 23 and has a central role in maintaining phosphate homeostasis. ${ }^{23}$ As $\alpha \mathrm{K} 1$ influences adipose cell maturation and glucose metabolism, $\alpha \mathrm{K} 1$ is regarded to have an essential role in whole-body energy metabolism. ${ }^{24}$ Furthermore, serum levels of saKl decrease in obese, chronic kidney disease, and diabetic patients. ${ }^{6,25,26}$

In the present study, we analyzed the association of $s \alpha \mathrm{Kl}$ levels with the progression of several pre-clinical disorders. We found that baseline serum levels of saKl were low in

Table 5 Baseline Serum Levels of saKI Subject with or without Hypertension Among Never-Smokers and Smokers

\begin{tabular}{|l|l|l|l|}
\hline & Never-Smoker & Smoker & P-value \\
\hline SBP/DBP $\geq 140 / 90 \mathrm{mmHg}$ & $450 \pm 111 \mathrm{pg} / \mathrm{mL}$ & $637 \pm 17 I^{*} \mathrm{pg} / \mathrm{mL}$ & 0.041 \\
SBP/DBP $<140 / 90 \mathrm{mmHg}$ & $486 \pm 185 \mathrm{pg} / \mathrm{mL}$ & $518 \pm 148 \mathrm{pg} / \mathrm{mL}$ & 0.499 \\
P-value & 0.580 & 0.125 & \\
\hline
\end{tabular}

Notes: ${ }^{*} \mathrm{P}<0.05$ versus never-smoker. Abbreviations are as in Table I.

Abbreviations: SBP, systolic blood pressure; DBP, diastolic blood pressure. 
subjects progressing to a high FPG level. Serum levels of s $\alpha \mathrm{K}$ also exhibited a similar relationship with other pre-clinical disorders. We further identified that a low level of $s \alpha \mathrm{Kl}$ was independent predictive factor for the progression of a high FPG level. Moreover, in subjects with low baseline, saKl were more likely to progress to a high FPG level. These results suggest that subjects with low serum levels of s $\alpha \mathrm{Kl}$ are likely to develop the pre-clinical state of disorders.

We used BMI and WC as pre-clinical disorder assessment for overweight and abdominal obesity, respectively. The relationship between s $\alpha \mathrm{Kl}$ levels and WC showed the same tendency as other disorders; however, BMI showed a different tendency. Since WC relates strongly to visceral fat accumulation, WC might associate with other disorders more strongly than BMI. ${ }^{27,28}$

We previously reported that serum levels of $\mathrm{s} \alpha \mathrm{Kl}$ were upregulated by smoking and psychological stress in healthy subjects. ${ }^{13,14}$ As $\alpha \mathrm{Kl}$ levels are reported to be reduced in patients with chronic obstructive pulmonary disease and depressive symptoms; diseases which are caused by smoking and psychological stress, respectively, ${ }^{29,30}$ increased serum levels of saKl may be a protective response to prevent disease progression. $\mathrm{s} \alpha \mathrm{Kl}$ levels in never-smoker subjects progressing to hypertension tended to be lower than in subjects without such progression. Moreover, in the never-smoker group, there was a larger difference of saKl levels in those progressing to a high FPG level than in the entire subjects. Excluding the influence of smoking, the difference of saKl levels between the subjects with and without progression of pre-clinical disorders was more obvious.

$\alpha \mathrm{K} 1$ has several protective effects. For example, $\alpha \mathrm{Kl}$ regulates vascular function by improving endothelial dysfunction. It is reported that delivery of the Klotho gene decreased blood pressure and reduced medial hypertrophy of the aorta, and perivascular fibrosis of the coronary artery, in an animal model that displayed multiple atherogenic risk factors. ${ }^{31}$ Moreover, $\alpha \mathrm{Kl}$ exerts an anti-inflammatory effect by suppressing the TNF- $\alpha$-induced expression of adhesion molecules, NF-kB activation, and RIG-I-mediated activation of IL- 6 and IL-8., ${ }^{9,32}$ In addition, serum levels of saKl revealed to have protective effects by suppressing cellular apoptosis, oxidative damage, and associating with proinflammatory status. ${ }^{11,12}$ We previously demonstrated that serum levels of $s \alpha \mathrm{K} 1$ were related with IL- 6 levels, and that increased saKl levels could be a compensatory response to inflammatory stress. ${ }^{13}$ Considering these protective aspects of $\alpha \mathrm{Kl}$ and s $\alpha \mathrm{Kl}$ levels, it is quite possible that increased $\mathrm{s} \alpha \mathrm{Kl}$ levels would prevent the progression of various disorders and disease.
As with metabolic syndrome, people tend to suffer multiple disorders simultaneously. Therefore, we assessed differences in serum levels of s $\alpha \mathrm{K} 1$ in subjects according to the number of disorders they displayed. Although we could not find a significant difference, subjects with multiple disorders progression tended to show lower serum levels of $\mathrm{s} \alpha \mathrm{K} 1$, suggesting that extremely low levels of s $\alpha \mathrm{Kl}$ might enable or cause the progression of multiple disorders. This finding also supports our hypothesis that high serum levels of $s \alpha \mathrm{Kl}$ prevent the progression of several pre-clinical disorders.

This study has some limitations. Since the study was exploratory research to find a new predictive marker for the pre-clinical disorder, the sample size was set in small size. Even though the sample size was small, we could detect a statistically significant effect of saKl. We are willing to confirm the result in a lager sample size in our further study. Another limitation is that all subjects were recruited from a single center. To confirm the effect of $\mathrm{s} \alpha \mathrm{Kl}$, a multicenter study is preferable in the future study.

\section{Conclusion}

We evaluated the association between serum levels of s $\alpha \mathrm{Kl}$ and the progression of several pre-clinical disorders. Subjects with low baseline serum levels of $s \alpha \mathrm{Kl}$ developed a high FPG level. Moreover, s $\alpha \mathrm{K} 1$ levels in subjects with multiple disorders progression tended to present lower than those in subjects with no disorder progression.

\section{Acknowledgments}

The authors would like to thank all the nurses and technicians who helped collect the data. The authors would also like to thank all the study participants.

\section{Funding}

This work was supported by JSPS KAKENHI (Grant Number JP18K17923).

\section{Disclosure}

The authors report no conflicts of interest in this work.

\section{References}

1. Wilson PW, D'Agostino RB, Parise H, Sullivan L, Meigs JB Metabolic syndrome as a precursor of cardiovascular disease and type 2 diabetes mellitus. Circulation. 2005;112(20):3066-3072. doi:10.1161/CIRCULATIONAHA.105.539528

2. Chei CL, Yamagishi K, Tanigawa T, et al. Metabolic syndrome and the risk of ischemic heart disease and stroke among middle-aged Japanese. Hypertens Res. 2008;31(10):1887-1894. doi:10.1291/hypres.31.1887 
3. Wu J, Qiu L, Cheng XQ, et al. Hyperuricemia and clustering of cardiovascular risk factors in the Chinese adult population. Sci Rep. 2017;7(1):5456. doi:10.1038/s41598-017-05751-w

4. Martin-Nunez E, Donate-Correa J, Muros-de-Fuentes M, MoraFernandez C, Navarro-Gonzalez JF. Implications of klotho in vascular health and disease. World J Cardiol. 2014;6(12):1262-1269. doi:10.4330/wjc.v6.i12.1262

5. Zhou HJ, Li H, Shi MQ, et al. Protective effect of klotho against ischemic brain injury is associated with inhibition of RIG-I/NF- $\mathrm{KB}$ signaling. Front Pharmacol. 2017;8:8. doi:10.3389/fphar.2017.00950

6. Nie F, Wu D, Du H, et al. Serum klotho protein levels and their correlations with the progression of type 2 diabetes mellitus. $J$ Diabetes Complications. 2017;31(3):594-598. doi:10.1016/j. jdiacomp.2016.11.008

7. Kuro-o M, Matsumura Y, Aizawa H, et al. Mutation of the mouse klotho gene leads to a syndrome resembling ageing. Nature. 1997;390(6655):45-51. doi:10.1038/36285

8. Suga T, Kurabayashi M, Sando Y, et al. Disruption of the klotho gene causes pulmonary emphysema in mice. Defect in maintenance of pulmonary integrity during postnatal life. Am J Respir Cell Mol Biol. 2000;22(1):26-33. doi:10.1165/ajrcmb.22.1.3554

9. Maekawa Y, Ishikawa K, Yasuda O, et al. Klotho suppresses TNF-alpha-induced expression of adhesion molecules in the endothelium and attenuates NF-kappaB activation. Endocrine. 2009;35 (3):341-346. doi:10.1007/s12020-009-9181-3

10. Yamazaki Y, Imura A, Urakawa I, et al. Establishment of sandwich ELISA for soluble alpha-Klotho measurement: age-dependent change of soluble alpha-Klotho levels in healthy subjects. Biochem Biophys Res Commun. 2010;398(3):513-518. doi:10.1016/j.bbrc.2010.06.110

11. Ravikumar P, Ye J, Zhang J, et al. Alpha-klotho protects against oxidative damage in pulmonary epithelia. Am J Physiol Lung Cell Mol Physiol. 2014;307(7):L566-575. doi:10.1152/ajplung.00306.2013

12. Martin-Nunez E, Donate-Correa J, Ferri C, et al. Association between serum levels of klotho and inflammatory cytokines in cardiovascular disease: a case-control study. Aging. 2020;12(2):1952-1964. doi:10.18632/aging.102734

13. Nakanishi K, Nishida M, Harada M, et al. Klotho-related molecules upregulated by smoking habit in apparently healthy men: a cross-sectional study. Sci Rep. 2015;5(1):14230. doi:10.1038/ srep 14230

14. Nakanishi K, Nishida M, Taneike $M$, et al. Implication of alpha-klotho as the predictive factor of stress. J Investig Med. 2019;67(7):1082-1086. doi:10.1136/jim-2018-000977

15. Navarro-Gonzalez JF, Donate-Correa J, Muros de Fuentes M, PérezHernández H, Martínez-Sanz R, Mora-Fernández C. Reduced klotho is associated with the presence and severity of coronary artery disease. Heart. 2014;100(1):34-40. doi:10.1136/heartjnl-2013304746

16. Examination Committee of Criter T, Examination Committee of Criteria for 'Obesity Disease' in J, Japan Society for the Study of O. New criteria for 'obesity disease' in Japan. Circ J. 2002;66 (11):987-992. doi:10.1253/circj.66.987

17. Shimamoto K, Ando K, Fujita T, et al. The Japanese society of hypertension guidelines for the management of hypertension (JSH 2014). Hypertens Res. 2014;37(4):253-390.

International Journal of General Medicine

\section{Publish your work in this journal}

The International Journal of General Medicine is an international, peer-reviewed open-access journal that focuses on general and internal medicine, pathogenesis, epidemiology, diagnosis, monitoring and treatment protocols. The journal is characterized by the rapid reporting of reviews, original research and clinical studies
18. Yamanaka H. Japanese guideline for the management of hyperuricemia and gout: second edition. Nucleosides Nucleotides Nucleic Acids. 2011;30(12):1018-1029. doi:10.1080/15257770.2011.596496

19. Kinoshita M, Yokote K, Arai H, et al. Japan atherosclerosis society (JAS) guidelines for prevention of atherosclerotic cardiovascular diseases 2017. $J$ Atheroscler Thromb. 2018;25(9):846-984. doi:10.5551/jat.GL2017

20. Haneda $M$, Noda $M$, Origasa $H$, et al. Japanese clinical practice guideline for diabetes 2016. J Diabetes Investig. 2018.

21. DeLong ER, DeLong DM, Clarke-Pearson DL. Comparing the areas under two or more correlated receiver operating characteristic curves: a nonparametric approach. Biometrics. 1988;44(3):837-845. doi: $10.2307 / 2531595$

22. Mendis S, Davis S, Norrving B. Organizational update: the world health organization global status report on noncommunicable diseases 2014; one more landmark step in the combat against stroke and vascular disease. Stroke. 2015;46(5):e121-122. doi:10.1161/ STROKEAHA.115.008097

23. Kuro OM. The klotho proteins in health and disease. Nat Rev Nephrol. 2019;15(1):27-44. doi:10.1038/s41581-018-0078-3

24. Razzaque MS. The role of klotho in energy metabolism. Nat Rev Endocrinol. 2012;8(10):579-587. doi:10.1038/nrendo.2012.75

25. Amitani M, Asakawa A, Amitani H, et al. Plasma klotho levels decrease in both anorexia nervosa and obesity. Nutrition. 2013;29 (9):1106-1109. doi:10.1016/j.nut.2013.02.005

26. Shimamura Y, Hamada K, Inoue K, et al. Serum levels of soluble secreted alpha-klotho are decreased in the early stages of chronic kidney disease, making it a probable novel biomarker for early diagnosis. Clin Exp Nephrol. 2012;16(5):722-729. doi:10.1007/ s10157-012-0621-7

27. Neeland IJ, Ross R, Despres JP, et al. Visceral and ectopic fat, atherosclerosis, and cardiometabolic disease: a position statement. Lancet Diabetes Endocrinol. 2019;7(9):715-725. doi:10.1016/ S2213-8587(19)30084-1

28. Despres JP, Lemieux I. Abdominal obesity and metabolic syndrome. Nature. 2006;444(7121):881-887. doi:10.1038/nature05488

29. Gao W, Yuan C, Zhang J, et al. Klotho expression is reduced in COPD airway epithelial cells: effects on inflammation and oxidant injury. Clin Sci (Lond). 2015;129(12):1011-1023. doi:10.1042/ CS20150273

30. Prather AA, Epel ES, Arenander J, et al. Longevity factor klotho and chronic psychological stress. Transl Psychiatry. 2015;5(6):e585. doi:10.1038/tp.2015.81

31. Saito Y, Nakamura T, Ohyama Y, et al. In vivo klotho gene delivery protects against endothelial dysfunction in multiple risk factor syndrome. Biochem Biophys Res Commun. 2000;276(2):767-772. doi: $10.1006 /$ bbrc. 2000.3470

32. Liu F, Wu S, Ren H, Gu J. Klotho suppresses RIG-I-mediated senescence-associated inflammation. Nat Cell Biol. 2011;13 (3):254-262. doi:10.1038/ncb2167

across all disease areas. The manuscript management system is completely online and includes a very quick and fair peer-review system, which is all easy to use. Visit http://www.dovepress.com testimonials.php to read real quotes from published authors. 